\title{
Robert Grosseteste and the Colours
}

\section{Amelia Carolina Sparavigna'}

\author{
${ }^{1}$ Department of Applied Science and Technology, Politecnico di Torino, Italy
}

\begin{abstract}
Here we discuss the De Colore, one of the short scientific treatises written by Robert Grosseteste in the mid-1220s. In this treatise, Grosseteste continues the discussion on light and colours he started in the De Iride. The medieval scientist describes two manners of counting colours: one gives an infinity of tones, the other counts seven essential colours. In both cases, colours are created by the purity or impurity of the transparent medium when light is passing through it. This was the medieval explanation of colours that survived until Newton's experiments with prisms.
\end{abstract}

Keywords: History of Science, Medieval Science

\section{Introduction}

In a recent paper [1], I proposed a translation and discussion of the De Iride, On the Rainbow, a treatise written by the medieval scholar Robert Grosseteste [2], probably in the early XIII Century. De Iride can be subdivided in two parts: the first is discussing reflection and refraction of light, the second part is devoted to the rainbow and has a short discussion of colours. In the mid-1220s, Grosseteste probably composed another very short treatise, the "De Colore", On Colours, where he further discusses the generation of colours from light and matter.

Before reading the "De Colore", let us shortly remember was Grosseteste proposed in the De Iride [1]. He supposed that colours are coming from the interaction of light with more or less transparent media: color sit lumen admixtum cum diaphano, he wrote. He continued enumerating the features of transparent media and light: a medium is diversified according to its purity and impurity, but the light is fourfold divided. The light is to be divided according to the brightness (claritas), and, of course, obscurity, and according to intensity (multitudo) and tenuity. From these features, the colours arise: secundum harum sex differentiarum connumerationes sint omnium colorum generationes et diversitates, varietas coloris in diversis partibus unius et eiusdem iridis maxime accidit propter multitudinem et paucitatem radiorum solis, that is, according to the six different enumerations [3], the variety of all the colours is generated, colours that appear in the different parts of a rainbow, mainly due to the intensity or tenuity of the rays of sun.

In the "De Iride", Grosseteste does not tell us what the colours are, that is, he does not write down a list of colours. Only one is mentioned, the Hyacinthus: ubi enim est maior radiorum multiplicatio, apparet color magis clarus et luminosus; ubi vero minor est radiorum multiplicatio, apparet color magis attinens hyacinthine et obscuro. Where there is a greater intensity of light, it appears that the colors are more luminous and bright: but where there is less intensity of light, it appears that the colour turns to the dark colour of Hyacinthus.

The hyacinthos is the name of a blue cornflower [4]. We know by its description in the Natural History of Pliny the Elder that, for the Latin world, the hyacinthos was a precious stone too. Pliny tells that it was very different from amethysts. The great difference between amethyst and hyacinthos is that "the brilliant violet which is so refulgent in the amethystos, is diluted in the other stone" [5]. John Bostock, who translated the Pliny's History, reports that this could be the name of the oriental amethyst or violet sapphire, not the hyacinthine of the modern English, meaning a stone of a yellowish colour, as in yellow zircon. The colour then described by Grosseteste was a violet one.

As previously told, in the mid-1220s, Grosseteste composed the De Colore, where he is discussing the generation of colours too. Here a translation is given from the Latin text of Reference 6. Before reading it, let us tell that, to Grosseteste, the colours are created by the purity or impurity of the transparent medium when light is passing through it. This was the medieval explanation of colours, which survived until Newton's experiments with prisms [7].

\section{On Colours}

Colour is light incorporated in a transparent medium. In fact, there are two different media: there are pure transparent media separated from earth materials or impure media mixed with them. And the light is four-fold differentiated: there is the bright and the obscure light, and the intense or the tenuous light. I do not say that an intense light is a light diffused by a great object, but it is the light that we can observe in a point where a large amount of it is collected by 
means of a concave mirror, and the light falling on the entire surface of the mirror facing the sun is reflected in the center of the sphere of the mirror. And then the power of light collected in this center ignites immediately a combustible material. So, an intense bright light in a transparent pure medium is the white. Tenuous light in an impure medium is black. And by telling this, we are explaining what Aristotle and Averroes told, who consider that blackness is lack of light and whiteness is richness in the appearance of light.

It also follows from this speech, that the colours near the white, in which we can arrive regressing from the whiteness and by variation, are seven, neither more nor less. Similarly, there will be seven colours near the black, which we find when progressing from darkness towards whiteness, until we have a combination with the other seven colours, to which we arrive descending from white. Since the essence of whiteness is made of three features, the intensity of light, its brightness and the purity of the transparent medium, two of them remaining fixed as we like, the third can be relaxed, and then this is how three colours are created; or anyone of these three features remains fixed, and the other two relaxed, and so will have other three colours, besides the three colours of the first triple generation; or all the three features are at the same time relaxed, and so the overall seven colours from the whiteness will directly obtained.

A similar procedure exists, by means of which we can show that through seven colours from the blackness we can progress towards the white. In general then, sixteen combinations would be: two of course are the ends (white and black), and seven at one end, attached to it by the tension of ascending, and, at the other end, by the remission of descending, merging in the same colours in the middle. Now, in any of the intermediate colours, the grades of tension and remission are infinite. Hence, by counting and combining the features, which can be intensified and released, that is, the intensity, the brightness of light and the purity of transparent media and their opposites, the essential colours that we can obtain are nine. By counting the degrees of tension and remission we have an infinite number of tones of intensity.

Now then, it is clear to whom who knew deeply and inwardly the principles of the natural science and of optics, not only by reasoning, but also by experience, that we have, according to the manner stated above, the essence of colours and their multitude. That is, knowing how to form a transparent medium, whether it were pure or impure, in such a way to receive a bright light, or, if it is preferred a dark light, and through the devised form in this very transparent medium, the light is reduced, or multiplied at pleasure; and so through the skill of combining all the modes, the colours that we want can be rendered visible. This is the end of the treatise on colours by a Lincolnian.

\section{Discussion}

Colour is light incorporated in a transparent medium. But we can have different media: pure and transparent media or earth materials, or their mixtures. In the same manner the light has different features. One is its intensity: to explain it, Grosseteste talks about the concave mirrors and the focusing of rays. In the Latin text, he is defining the intensity as the "lux multa", because he is clearly referring to the focus of the mirror, where we can have a "radiorum multiplicatio", multiplication of rays, because in the focus we collect several rays of light.

Grosseteste is distinguishing pure and impure transparent media, impure because of the mixture with earth materials. "Earth" is one of the four classical elements in ancient Greek philosophy and science, commonly associated with qualities of heaviness and matter [8]. Here we can associate the earth materials to the defects and the impurities that we have in transparent media such as crystals. However, since Grosseteste is discussing about colours, we could also suppose that he was trying to merge the pure colours that we can see in the dispersion by a prism to those that we can obtain using pigments. We have for instance the earth pigments for painting, some of them well known since prehistoric times. The clay earth pigments, ochre and sienna for instance, are naturally occurring minerals, principally iron oxides. For what concerns the dispersion of light from prisms, this was a phenomenon described even in the Natural History by Pliny the Elder [5]. Since this book was one of the ancient books that the scholars of the Middle Age used for their treatises on Nature, it is quite probable that Grosseteste experimented with prisms, even if he did not discuss the phenomenon in his treatises.

Grosseteste defines white and black. An intense bright light in a transparent pure medium is the white. Tenuous light in an impure medium is black. "And by telling this, we are explaining what Aristotle and Averroes told, who consider that blackness is lack of light and whiteness is richness or appearance if light". And also, "et hic intendebat Philosophus per 'nigredinem' privationem albedinis", wrote Henricus Bate, a Flemish astronomer around 1300 [9], in his Speculum divinorum et quorundam naturalium [10]. Of course, we could imagine a symbolic meaning too [11]. In the early Middle Ages, Reference 11 tells that black was commonly associated with darkness and evil. Clothes of black colour were worn by Benedictine monks as a sign of humility and penitence. In the $12^{\text {th }}$ century a theological dispute 
about the colours of clothes broke out between the Cistercian monks, who wore white, and the Benedictines. Pierre the Venerable, a Benedictine, accused the Cistercians of excessive pride in wearing white, but Saint Bernard of Clairvaux, founder of the Cistercians, replied that black was the color of the devil, while white represented purity and "all the virtues" [11,12]. Let us also note that "albedo", the whiteness, is one of the four major stages of the "magnum opus" of the alchemy; along with nigredo, citrinitas and rubedo. From the nigredo stage, the alchemist undertakes a purification in albedo, passing through a chromatic sequence [13].
Grosseteste continues telling that the colours near the white, in which we can arrive regressing from the whiteness and by variation, are seven. Similarly, there will be seven colours near the black, that we find when progressing from darkness towards whiteness, until we have a combination with the other seven colours, to which we arrive descending from white. Let us see how the other colours are created. For example, the white is given by brightness, intensity and purity: we can relax one, two or all these three features to obtain seven colours, as in the calculus of combinations shown in the Figure 1.

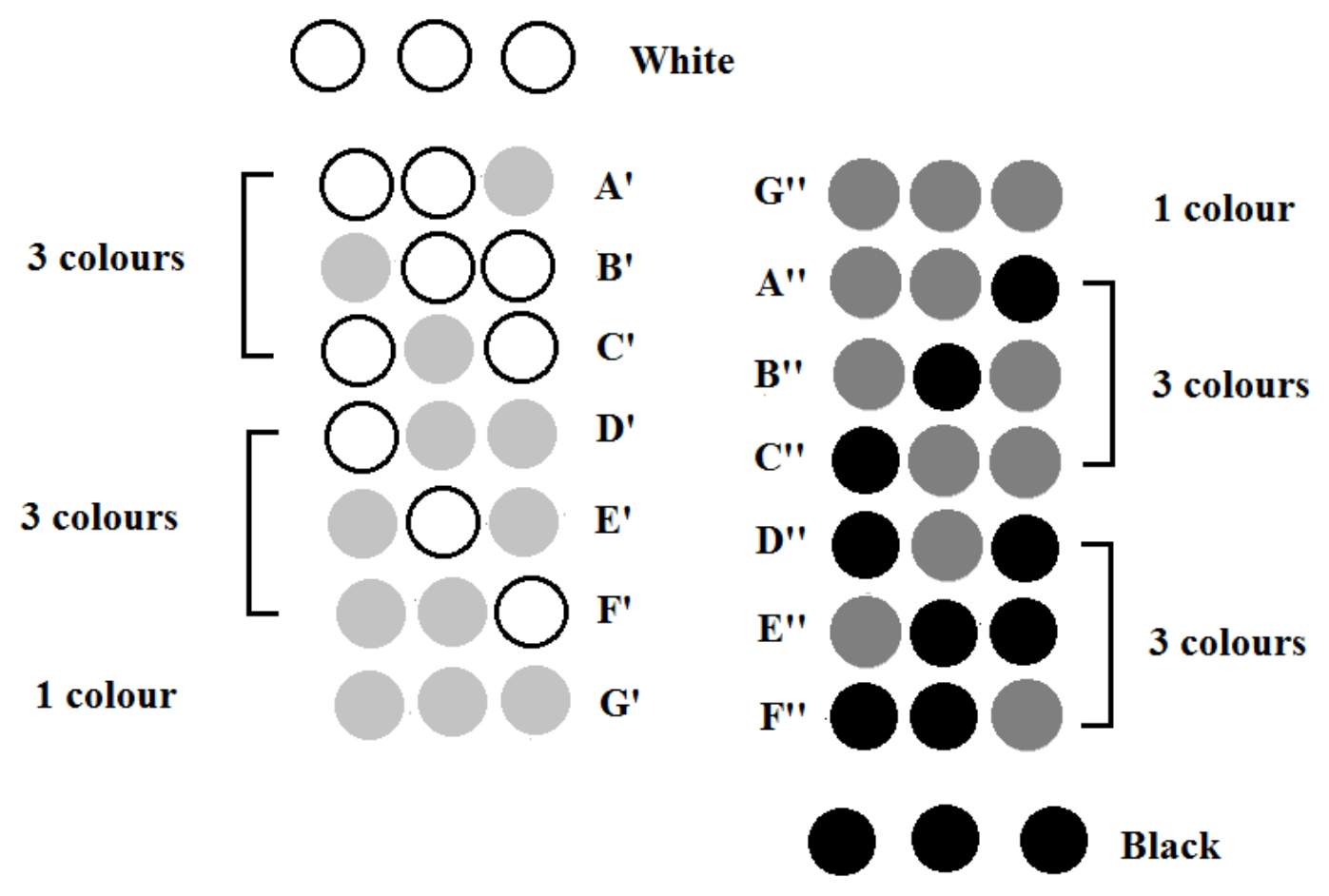

Figure 1 - The colours can be created by white, which is brightness, intensity and purity.

We can relax one, two or all these three features to obtain seven colours, as in the calculus of combinations. The relaxation of one of the white features is rendered by a grey circles.

The same we can do from the black.

A similar procedure exists starting from the black. So we have sixteen combinations: two are the ends (white and black), and fourteen near them. But, by changing the intensity of light and the purity of transparent media, the colours from black merge with colours from white, and then we have nine colours. That is: white, black and seven colours. At Reference 14, there is a quite interesting image related to the Grosseteste's theory, which is here adapted in the Figure 2. 


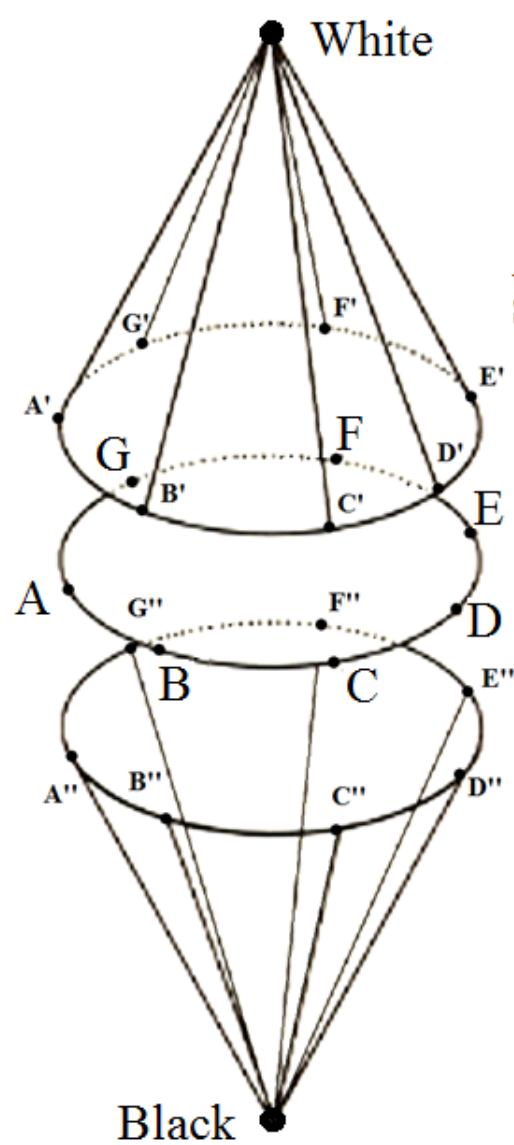

$\mathrm{A}^{\prime}, \mathrm{B}^{\prime}, \mathrm{C}^{\prime}, \mathrm{D}^{\prime}, \mathrm{E}^{\prime}, \mathrm{F}^{\prime}, \mathrm{G}^{\prime}$

Seven colours from White

A,B,C,D,E,F,G

the seven colours in

the middle

A",B",C",D",E",F",G"

Seven colours from Black

Nine colours:

White, Black and

$\mathrm{A}, \mathrm{B}, \mathrm{C}, \mathrm{D}, \mathrm{E}, \mathrm{F}, \mathrm{G}$

Figure 2 - The seven colours from white and the seven colours from black are merging in "average" colours, which gives a circle of seven colours [14]. White, black and these seven colours provide nine colours.

In it we can see that, from white we have seven colours, and seven colours from black. But these colours move on two cones, merging in the middle, where we have seven "average" colours. We can define them as the seven essential colours, that, with white and black, give the nine colours mentioned by Grosseteste. However, if we consider "the degrees of tension and remission", there will be an infinite number of tones of intensity. That is, Grosseteste counted the colours in two manners: the first is that based on combinations (Figure 1), the second is based on a continuous scale of tones, as we can have in a palette of the Paint software for instance. As shown in the Figure 3 we have an infinite number of greens: in any case, it is green. 

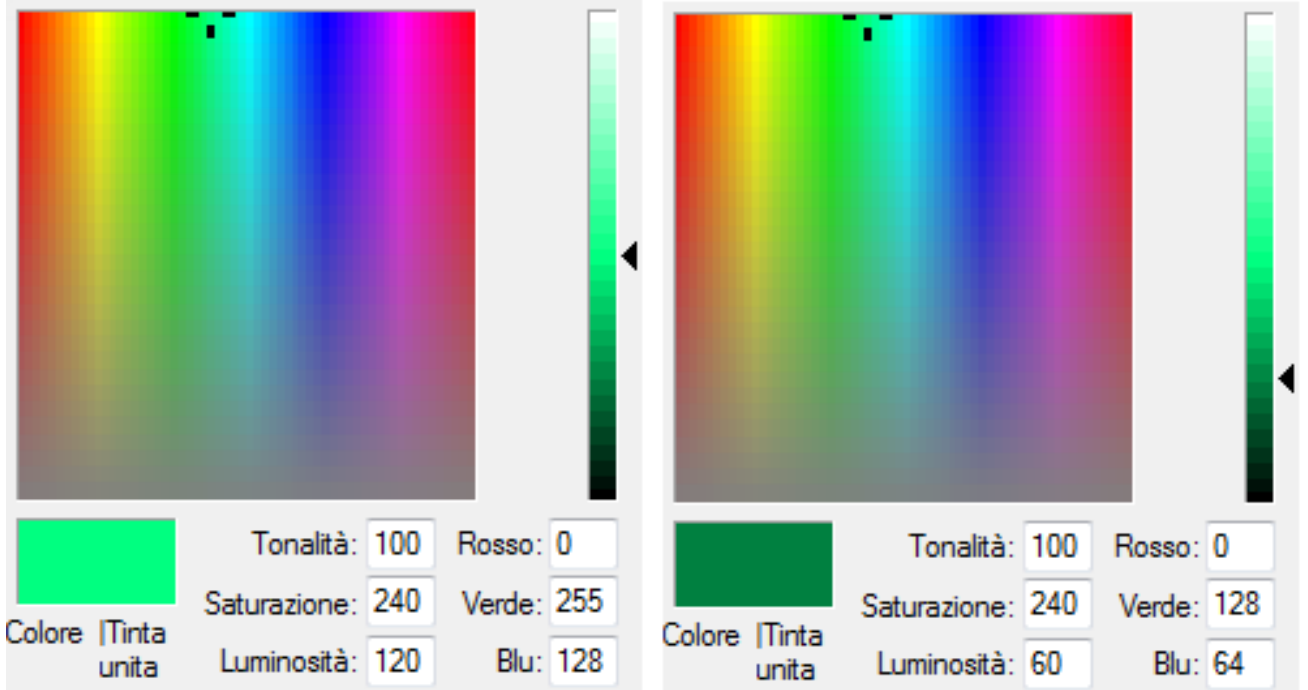

Figure 3 - An example from the palette of Paint software. We see a light green and a dark green. In any case, it is green.

A recent discussion of the Grosseteste's colours in the RGB space has been proposed in Reference 15. In the paper, the authors are arguing that the colour space described by Grosseteste is explicitly threedimensional. For what concerns the Latin text, let us note that Grosseteste is using, to describe the light, the terms "lux" and "lumen". In Reference 16, it is proposed that lux is light in its source, whereas lumen is reflected or radiated light.

In the Figure 2, adapted from [14], we see a circle of colours obtained considering the average of the colours coming from white and black. Sir Isaac Newton proposed a circle of colours containing seven colours too. He called them Aureus, Flavus, Viridis, Caeruleus, Indicus, Violaceus and Rubeus. Newton used seven colours by analogy to the number of notes in a musical scale [17]. It would be interesting a comparison of Newton's colours with those of Grosseteste. However, Grosseteste did not provide the name of them, besides one, the Hyacinthus which is a Violaceus (violet) colour.

We can ask ourselves whether the Grosseteste's work had some influences until the Newton's times or not. It seems that this is so, as we can find in the book on the life of Sir Isaac Newton, written by David Brewster [18]. Let us consider what Brewster is telling on colours: he reports that Newton's friend and tutor, Isaac Barrow (1630-1677), delivered some optical lectures, which were published in 1669. "In the preface of this work - Brewster writes he acknowledges his obligations to his colleague, Mr. Isaac Newton, for having revised the manuscripts, and corrected several oversights, and made some important suggestions. In the twelfth lecture there are some observations on the nature and origin of colours ... According to Dr. Barrow, White is that which discharges a copious light equally clear in every direction; Black is that which does not emit light at all, or which does it very sparingly. Red is that which emits a light more clear than usual, but interrupted by shady interstices. Blue is that which discharges a rarified light, as in bodies which consist of white and black particles arranged alternately. Green is nearly allied to blue. Yellow is a mixture of much white and a little red; and Purple consists of a great deal of blue mixed with a small portion of red. The blue colour of the sea arises from the whiteness of the salt which it contains, mixed with the blackness of the pure water in which the salt is dissolved; and the blueness of the shadows of bodies, seen at the same time by candle and daylight, arises from the whiteness of the paper mixed with the faint light or blackness of the twilight" [18]. Here we find that the Grosseteste's framework of the combinations of the features of light (copious and clear) and of transparent media (pure or not) is maintained in the Barrow's approach to colours.

The first Newton's studies on prisms were made on 1666 , aiming to improve the optical instruments, in particular telescopes. He found the white light a mixture of colours refracted differently by a transparent medium. Experimenting with two prisms, he showed that a second prism can be used to put back together the light into white light [18]. If the origin of colours were the impurity of the transparent medium, this recombination would be impossible. Newton therefore, with his experiments, disrupted the medieval framework of optics, showing that it is not the purity or impurity of a medium that, interacting with light, gives the colours, but the different refractions of the components of the white light. 


\section{References}

[1] A.C. Sparavigna, On the Rainbow, a Robert Grosseteste's Treatise on Optics, The International Journal of Sciences, 2013, Volume 2, Issue 9, Pages 108-113.

[2] N. Lewis, Robert Grosseteste, The Stanford Encyclopedia of Philosophy, Winter 2010 Edition, http://plato.stanford.edu/entries/grosseteste/

[3] These six features are purity and impurity for the medium and brightness, obscurity, intensity and tenuity for light.

[4] D. Harper, Online Etymology Dictionary, http://www.etymonline.com/index.php

[5] Pliny the Elder, The Natural History, translated by John Bostock, London. Taylor and Francis, Red Lion Court, Fleet Street, 1855.

[6] The Latin text is that given by "The Electronic Grosseteste", http://www.grosseteste.com/, which is reporting the printed Source: Die Philosophischen Werke des Robert Grosseteste, Bischofs von Lincoln, W. Aschendorff, 1912.

[7] A.C. Sparavigna, The Play of Colours of Prisms, arXiv:1207.3504, arXiv, 2012.

[8] A.C. Sparavigna, Robert Grosseteste and the Four Elements, The International Journal of Sciences, 2013, Volume 2, Issue 12, Pages 42-45.
[9] H. Grabes, The Mutable Glass: Mirror Imagery in Titles and Texts of the Middle Ages and the English Renaissance, Cambridge University Press, 1982, pag.43.

[10] Henricus Bate, Speculum Divinorum et Quorundam Naturalium, parts XIII-XVI, edited by Guy Guildentops, Leuven University Press, 2002.

[11] http://en.wikipedia.org/wiki/Black\#The_Middle_Ages

[12] M. Pastoureau, Noir: Histoire d'Une Couleur, Paris, Seuil, 2008 .

[13] H. Gebelein, Alchimia, la Magia della Sostanza, 2009, Edizioni Mediterranee, Roma.

[14] N. Silvestrini and E.P. Fischer, Colorsystem, Colour Order Systems in Art and Science, at www.colorsystem.com

[15] H.E. Smithson, G. Dinkova-Bruun, G.E.M. Gasper, M. Huxtable, T.C.B. McLeish, and C. Panti, A Three-Dimensional Color Space from the $13^{\text {th }}$ Century, J. Opt. Soc. Am. Opt. Image Sci. Vis., 2012, Volume 29, Issue 2, Pages A346-A352.

[16] C.C. Riedl, Robert Grosseteste On light, Marquette University Press, Milwaukee, Wisconsin, 1942.

[17] D. Allchin, Newton's Colors, SHiPS Resource Center. Retrieved 2010-10-16.

[18] David Brewster, The Life of Sir Isaac Newton, Harper \& Brothers, New York, 1840. 